Slavica

bruxellensia

\section{Slavica bruxellensia}

Revue polyphonique de littérature, culture et histoire

slaves

$5 \mid 2010$

Après 1989

\title{
Avestian V. A., Posledne sobesedniki Puškina. Eščë raz o probleme Puškin-Goethe
}

\section{Brice Thissen}

\section{OpenEdition}

\section{Journals}

Édition électronique

URL : http://journals.openedition.org/slavica/312

DOI : $10.4000 /$ slavica.312

ISSN : 2034-6395

\section{Éditeur}

Université libre de Bruxelles - ULB

\section{Édition imprimée}

Pagination : 87-88

ISSN : 2037-7654

Référence électronique

Brice Thissen, «Avestian V. A., Posledne sobesedniki Puškina. Eščë raz o probleme Puškin-Goethe », Slavica bruxellensia [En ligne], 5 | 2010, mis en ligne le 09 juillet 2012, consulté le 22 septembre 2020. URL : http://journals.openedition.org/slavica/312 ; DOI : https://doi.org/10.4000/slavica.312

Ce document a été généré automatiquement le 22 septembre 2020

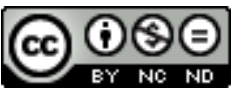

Les contenus de Slavica bruxellensia sont mis à disposition selon les termes de la Licence Creative Commons Attribution - Pas d'Utilisation Commerciale - Pas de Modification 3.0 France. 


\title{
Avestian V. A., Posledne sobesedniki Puškina. Eščë raz o probleme Puškin-Goethe
}

\author{
Brice Thissen
}

\section{RÉFÉRENCE}

Avestian V. A., Posledne sobesedniki Puškina. Ěšč raz o probleme Puškin-Goethe, Moscou, éd. R \& C Dynamics, 2009, 68 p.

1 Le problème principal dans l'étude des rapports littéraires entre Goethe et Puškin peut être formulé de la façon suivante : dans quelle mesure les travaux et la personnalité du romantique allemand étaient-ils connus du grand poète russe ? Il se peut tout à fait que la mort du poète soit survenue dans une période d'intenses travaux et de lectures.

Dans la première partie de Posledne sobesedniki Puškina... (Les derniers interlocuteurs littéraires de Pouchkine - encore une fois à propos du problème Puškin-Goethe), Avestian réactualise le problème, c'est-à-dire qu'il nous le présente dans son contexte historique et culturel en parcourant les salons littéraires allemands et russes, en passant par les rédactions de revues en Russie, en France ou en Angleterre. Cette démarche peut sembler quelque peu incongrue au lecteur, mais elle est parfaitement justifiée car nous sommes en effet en droit de nous demander quelle influence put avoir l'œuvre de Goethe sur celle de Puškin alors que ce dernier n'était pas assez familiarisé avec l'allemand que pour pouvoir lire dans le texte les ouvrages de son contemporain? C'est ici qu'entrent en jeu les importants travaux réalisés par les littérateurs français et anglais, dont Puškin maîtrisait les langues. De l'Allemagne de Madame de Staël, différentes publications françaises ou russes commentant des œuvres allemandes, divers articles portant sur les grandes esthétiques artistiques de l'époque (classicisme et romantisme) et les théories littéraires du moment (e. a. de Schelling et de Lessing) ont joué un rôle fondateur dans l'appréhension de la littérature allemande par Puškin. 
3 La deuxième partie de la brochure fait état de la relation entre les deux écrivains. L'auteur s'appuie sur des articles littéraires ainsi que sur des notes tirées de carnets personnels de contemporains de nos deux auteurs (Turgenev, Byron, etc.) pour comprendre à quels moments et par quels intermédiaires Puškin et Goethe se sont lus mutuellement. Ils trouvent un point de contact dans les conceptions développées sur l'arène littéraire européenne contemporaine, qu'ils contribuent à former et qu'ils proclament. Leur conception est d'ailleurs assez proche: tous deux proclament l'unification, par la littérature, de la culture européenne afin de conduire à un temps de paix. Il faut souligner qu'à cette époque, on assistait à un rapprochement des cercles littéraires européens : les créations anglaises, françaises, allemandes, mais aussi russes et polonaises se faisaient écho et s'inter-influençaient.

Dans la dernière section de cette publication, l'auteur tente de déterminer dans quelle mesure la création du premier à eu une influence sur celle du second. Il s'agit principalement de déterminer l'impact des Souffrances du Jeune Werther et du fameux Faust sur Evgenij Onégin. Une partie importante du rôle d'intermédiaire entre Goethe et Puškin est joué par la littérature anglaise et, il va sans dire, des deux des ses plus illustres représentants : Shakespeare et Byron. Le premier n'est contemporain d'aucun de nos deux auteurs, mais ses écrits sont toujours lus avec autant d'intérêt au temps du second, dont le rayonnement européen atteint jusque la Russie lointaine.

Dans quelle mesure Goethe connaissait-il l'œuvre de Puškin? Dans quelle mesure Puškin connaissait-il celle de Goethe? Ces questions restent actuelles. L'étude des rapports entre les deux génies littéraires peut seule nous apporter une réponse satisfaisante, qui sera à même de mettre en lumière ce que l'un doit à l'autre et, donc, expliquer une partie de leur " gigantisme».

6 La seule critique que je formulerai concerne la structure du livre. Celle-ci n'est détaillée nulle part, la table des matières ne reprend qu'une bibliographie «littéraire » et les parties en elles-mêmes ne sont séparées les unes des autres que par un interligne un peu plus grand.

INDEX

Mots-clés : littérature russe

Index chronologique : XIXe siècle

Index géographique : Allemagne, Russie

\section{AUTEURS}

BRICE THISSEN

Étudiant à l'Université Libre de Bruxelles en Langues et Littératures modernes, orientation slaves 